\title{
Very pure porcine insulin in clinical practice
}

\author{
A D WRIGHT, C H WALSH, M G FITZGERALD, J M MALINS
}

British Medical fournal, 1979, 1, 25-27

\section{Summary and conclusions}

In a one-year follow-up study the insulin dose in diabetic patients using very pure porcine insulin was compared with that in patients using conventional preparations. The dose of insulin used to obtain diabetic control was reduced by $7 \%$ in 108 patients treated solely with very pure porcine insulin from the start of insulin treatment when compared with 108 matched patients who had received conventional insulins. In 117 patients whose treatment had been changed from conventional bovine or bovine-porcine insulin to very pure porcine insulin the dose was reduced by $9 \%$. A further 511 patients receiving conventional insulins were examined for local cutaneous or subcutaneous abnormalities at insulin injection sites. Lipoatrophy was found in 49 of these patients $(10 \%)$, but not in patients using very pure porcine insulin.

The results confirm that very pure porcine insulin reduces the insulin dose needed to maintain diabetic control and may resolve or prevent local reactions such as lipoatrophy. Long-term advantages in reduced antigenicity to insulin and contaminating peptides remain to be established.

Diabetic Clinic, the General Hospital, Birmingham B4 6NH

A D WRIGHT, MB, FRCP, senior lecturer in medicine, University of Birmingham

C $H$ WALSH, MD, MRCP, senior registrar in medicine

M G FITZGERALD, MD, FRCP, consultant physician

J M MALINS, MD, FRCP, professor of medicine

\section{Introduction}

The immunogenicity of the recently introduced very pure porcine insulins (Actrapid MC, Semitard MC, Monotard MC, Leo Neutral, and Leo Retard) is minimal, with established advantages in treating insulin allergy, lipoatrophy, and some cases of insulin resistance. It is claimed that the dose of very pure porcine insulin used to obtain diabetic control is reduced by as much as $32 \%{ }^{1}$ We surveyed our clinical practice over the past three years to compare the insulin dose in patients using very pure porcine insulin with that in patients using conventional bovine or mixed porcine-bovine insulins in common use up to 1975 (mainly soluble, lente, isophane, and protamine zinc insulin). Firstly, we compared the dose used in patients receiving very pure porcine insulin from the start of insulin treatment with that in patients treated solely with conventional preparations, and secondly we compared the dose used in patients treated initially with conventional insulin, whose treatment was subsequently changed to very pure porcine insulin.

Lipoatrophy may occur in as many as $15 \%$ of insulin-treated adult patients. ${ }^{2}$ Nevertheless, no recent study indicates the incidence of lipoatrophy, lipomas, and other problems when the currently available conventional preparations are used, though some evidence suggests that lipoatrophy is less common with some insulins. ${ }^{3}$ To help any future assessment of the value of very pure porcine insulins in preventing local reactions we studied their incidence in patients treated with conventional insulins only.

\section{Patients and methods}

Three groups of adolescent and adult diabetic patients were studied separately. Ages and weights for the three groups are expressed as means \pm SE of mean.

Newly treated patients-This group comprised 108 patients (51 men, 57 women) who had regular clinic notes documenting insulin dose and body weight at roughly three months (range 2-4 months) 
and one year (range 11-15 months) from starting treatment with very pure porcine insulin. Their mean age was $54.7 \pm 1.72$ years and their mean weight at three months was $67.4 \pm 1.25 \mathrm{~kg}$ and at one year $69.5 \pm 1.24 \mathrm{~kg}$. Each of these 108 patients was matched for sex, age, and body weight at start of insulin treatment and type of insulin (insulin zinc suspension or isophane regimens) with an equivalent patient chosen at random from the clinic records of 10 years ago. The mean age ( $54 \pm 1.75$ years) of this conventional insulin group and their body weight at three months $(68.4 \pm 1.28 \mathrm{~kg}$ ) and one year $(71.3 \pm 1.35 \mathrm{~kg})$ was not different from the patients who received very pure porcine insulin. Patients who had serious intercurrent illness or who were pregnant were excluded.

Change of insulin-This group comprised 117 patients (44 men, 73 women; mean age $42.2 \pm 1.73$ years) who had been established on conventional insulins for at least six months and whose treatment was subsequently changed to very pure porcine insulin. In most patients treatment was changed because of difficulties in diabetic control or abnormalities at injection sites. Patients whose follow-up information was incomplete at roughly three months and one year after changing treatment and those whose dosage may have been affected by serious intercurrent illness or pregnancy were excluded. Three patients who changed back to conventional insulin within the year because of problems with hypoglycaemia were also excluded, as were the two patients who used more than 200 units of conventional insulin daily.

Injection sites-The insulin injection sites of 511 patients $(235$ male, 276 female; aged 12-90 years) attending the diabetic clinic in four consecutive months before the introduction of very pure porcine insulins were examined for any local cutaneous or subcutaneous abnormality. All patients had used conventional insulins for over three months. Three hundred and ninety-nine patients $(78 \%)$ were using a single injection a day and 112 patients $(22 \%)$ two injections a day, and 460 patients $(90 \%)$ were using insulin of $80 \mathrm{U} / \mathrm{ml}$ strength alone. The thighs and arms alone or in rotation were used for insulin injections by 409 patients $(80 \%)$, the remainder using other sites such as the abdomen or buttocks. Abnormalities at the injection sites were classified as lipoatrophy, lipoma, nodular fibrotic lesions, and transient (cutaneous lesions persisting for not more than a few days).

\section{Results}

Newly treated patients-The doses of insulin used in the patients treated with the very pure porcine insulin were not significantly different at three months and one year from those used in patients treated with conventional insulin (figure), although at one year the mean dose of very pure porcine insulin was $7 \%$ less than the mean dose of conventional insulin. Similar reductions were found when patients were subdivided according to sex, age, and type of insulin (table I). Patients aged under 50 used significantly more insulin than older patients when expressed as units/kg body weight, but this was true of both conventional and very pure porcine insulin.

Change of insulin-At one year after the change from conventional to very pure porcine insulin the mean dose fell by $9 \% \quad(\mathbf{P}<0.01)$ (table II). The mean reduction in dose was greater in those whose treatment was changed because of problems at injection site or other reasons $(13 \%)$ compared with those who had had difficulty in diabetic control $(8 \%)$, the change in the last group being non-significant on paired $t$ testing. When the percentage change was calculated for each individual patient, the mean reduction was $4 \%$ for the total group, $10.6 \%$ in the subgroup with injection-site abnormality, and essentially unchanged $(+0.2 \%)$ in the subgroup who had had difficulty in diabetic control.

Injection sites-Abnormalities were found in 207 patients (40\%)

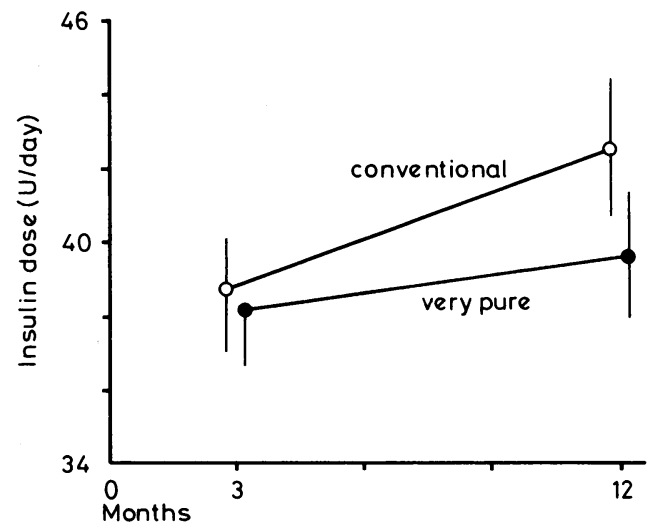

Dose of insulin at 3 months and 12 months from start of insulin treatment in 108 patients treated with very pure porcine insulins and in 108 matched patients using conventional bovine or porcine-bovine insulins. Differences between the two groups were not significant $(P<0.3$; unpaired $t$ test). Values are means $( \pm S E$ of mean).

TABLE II-Insulin dose at 3 months and 1 year in patients whose treatment was changed from conventional insulins to very pure porcine insulins, according to reason for change. Values are means $( \pm S E \text { of mean })^{*}$

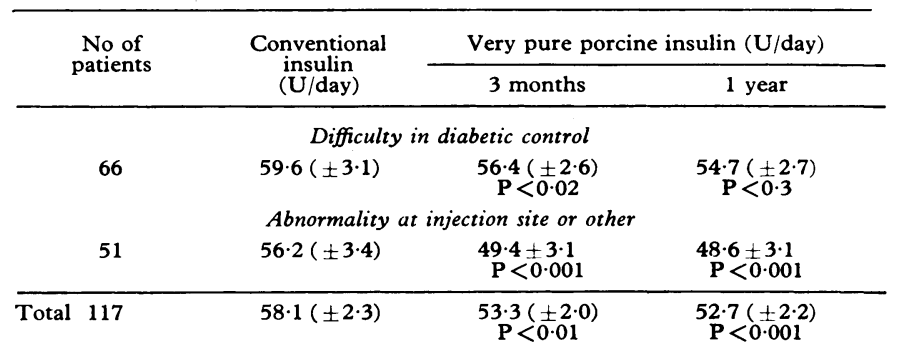

*P values derived from comparison with conventional insulin using paired $t$ test.

using conventional insulins (table III), and were more common in female than male patients $(P<0.01)$. Lipoatrophy was found in 49 patients $(10 \%)$, and was most common in women aged under 55 (23 patients; $20 \%$ ). Lipoatrophy was seen at all the injection sites in common use, but was not seen at a site away from an insulin injection. In 14 patients lipoatrophy was present at one site only and other sites in use were normal. The lipoatrophy was gross in seven, slight in 12 , and ungraded in the remaining patients. In the patients with lipoatrophy there was nothing to distinguish the type of insulin in current use or its strength or manufacturer, and a review of the records of these patients did not show any consistent pattern of insulin usage in the past.

Nodular fibrotic lesions, lipomas, and transient lesions at injection sites occurred equally in those aged under 55 compared with those aged over 55, and the type, strength, and manufacturer of conventional insulin seemed to be the same as those with normal injection sites. These abnormalities occurred at all the commonly used injection sites.

TABLE I-Insulin dose in newly treated patients after one year's treatment with very pure porcine insulins and in matched patients treated with conventional insulin, according to age, sex, and type of insulin. Values are means ( $\pm S E$ of mean)

\begin{tabular}{|c|c|c|c|c|c|c|c|}
\hline & & & \multirow{2}{*}{$\begin{array}{c}\text { No of } \\
\text { patients }\end{array}$} & \multicolumn{2}{|c|}{ Insulin (U/day) } & \multicolumn{2}{|c|}{ Insulin (U/kg/day) } \\
\hline & & & & Conventional & Very pure & Conventional & Very pure \\
\hline $\begin{array}{l}\text { Female patients } \ldots \\
\text { Male patients } \ldots \\
\text { Age }<50 \text { years } \\
\text { Age } \geqslant 50 \text { years } \\
\text { Insulin zinc suspension } \ddagger \\
\text { Protamine } \neq\end{array}$ & $\begin{array}{l}\because \\
\because \\
\because \\
\because\end{array}$ & $\begin{array}{l}\cdots \\
\because \\
\cdots \\
\cdots\end{array}$ & $\begin{array}{l}57 \\
51 \\
38 \\
70 \\
74 \\
34\end{array}$ & $\begin{array}{l}40( \pm 2 \cdot 34) \\
45 \cdot 4( \pm 2 \cdot 77) \\
46 \cdot 7( \pm 3 \cdot 57) \\
40 \cdot 2( \pm 2 \cdot 0) \\
41( \pm 2 \cdot 16) \\
44 \cdot 1( \pm 3 \cdot 0)\end{array}$ & $\begin{array}{l}38 \cdot 6( \pm 2 \cdot 44) \\
40.9( \pm 2 \cdot 6) \\
42 \cdot 9( \pm 3 \cdot 47) \\
37 \cdot 9( \pm 2 \cdot 02) \\
38 \cdot 8( \pm 2 \cdot 06) \\
41 \cdot 2( \pm 3.48)\end{array}$ & $\begin{array}{l}0.61( \pm 0.036) \\
0.58( \pm 0.035) \\
0.68( \pm 0.05)^{*} \\
0.56( \pm 0.026)^{*} \\
0.59( \pm 0.03) \\
0.62( \pm 0.046)\end{array}$ & $\begin{array}{l}0.6( \pm 0.037) \\
0.55( \pm 0.035) \\
0.64( \pm 0.05) \dagger \\
0.54( \pm 0.029)+ \\
0.57( \pm 0.032) \\
0.6( \pm 0.046)\end{array}$ \\
\hline
\end{tabular}


TABLE III-Insulin injection sites in patients using conventional insulins. Figures are numbers $(\%)$ of patients

\begin{tabular}{lllcc}
\hline \multicolumn{2}{c}{ Injection site } & & Female patients & Male patients \\
\hline Normal . & $\ldots$ & $\ldots$ & $148(54)$ & $156(67)$ \\
Lipoatrophy alone & $\ldots$ & $\ldots$ & $23(8)$ & $12(5)$ \\
Lipoatrophy and lipoma. & $\ldots$ & $7(3)$ & $2(1)$ \\
Lipoatrophy and nodules & $\ldots$ & $5(2)$ & $36(15)$ \\
Lipoma alone & $\ldots$ & $\ldots$ & $48(17)$ & 1 \\
Lipoma and nodules & $\ldots$ & $\ldots$ & $34(12)$ & $21(9)$ \\
Nodules alone & $\ldots$ & $\ldots$ & $11(4)$ & $7(3)$ \\
Transient abnormality & $\ldots$ & $\ldots$ & $276(100)$ & $235(100)$ \\
\hline
\end{tabular}

\section{Discussion}

Our results confirm that the overall dose of very pure porcine insulin needed to control diabetes is less than that of conventional insulin. A follow-up of over one year may be necessary to survey the dose used by both newly treated patients and those whose treatment has been changed to very pure porcine insulin before the exact difference can be determined. This may be particularly true in patients whose treatment has been changed to very pure porcine insulin, since a further reduction in serum insulin-binding capacity occurs in the second year in patients transferred to monocomponent insulin. ${ }^{1}$ The reduction in insulin dose of $19 \%$ to $32 \%$ reported by others ${ }^{14}$ over similar follow-up periods is considerably higher than that in our patients. One important difference in our patients who had changed insulin was that the mean dose of conventional insulin was lower. ${ }^{4}$ Hence, the method used to express the reduction in insulin dose will determine the precise result. For individual patients the percentage change ${ }^{6}$ is probably more important than the mean change in $U /$ day for the total group, which may be affected by a few patients receiving high doses whose changes in requirements are correspondingly greater. For this reason we omitted the two patients who were changed to very pure porcine insulin because of insulin resistance when receiving conventional insulin.

Our studies do not distinguish between the effect of changing species of insulin and changing purity. Both factors may be important. ${ }^{4}$ We agree that it is wise to expect an immediate reduction of $20 \%$ in dose when a patient who has been stabilised on a large dose of conventional insulin is then changed to very pure porcine insulin, but this is not necessary in patients receiving average doses or less. We have not seen the immediate fall of $36 \%$ reported by Stowers and Logie ${ }^{7}$ in a patient who had been insulin resistant and was changed from Actrapid to Actrapid MC. More commonly, we have found that the reduction in dose occurs more gradually during the first three months after changing. On transferring some patients from conventional to very pure porcine insulin the dose used actually increases, even when the reason for change is not difficulty in diabetic control.

The control of diabetes achieved with very pure porcine insulins does not seem to be different from conventional insulin, although, in keeping with another report, ${ }^{8}$ we have found that similar doses of Actrapid MC or Leo Neutral insulin may cause sudden and more severe hypoglycaemic reactions than soluble insulin. We have also found that duration of action of Monotard MC insulin appears somewhat shorter than that of lente insulin.

Lipoatrophy remains an important problem in patients receiving conventional insulin, particularly younger female patients, and may resolve when treatment is changed to very pure porcine insulin. ${ }^{59}$ Our results with very pure porcine insulin are incomplete, but show improvement or resolution in all of seven patients who were followed for nine months or more after changing from conventional insulin. Patients treated solely with very pure porcine insulin did not develop lipoatrophy. Lipomas are the most common abnormality at injection sites in patients receiving conventional insulin, but established lesions show little change, and occasionally increase in size, when very pure porcine insulin is given. Indeed, we have observed an appreciable lipoma in a patient treated solely with very pure porcine insulin. Nodular fibrotic lesions are probably due to faulty injection technique in too small an area and may occur with any insulin preparation. Acute allergic phenomena are rarely seen at injection sites when very pure porcine insulin is used. One such episode in one of our patients using Monotard MC was shown to be due to contamination of the insulin by industrial spirit.

Very pure porcine insulins reduce the antibody response to insulin and probably eliminate antibody response to the contaminating peptides found in conventional insulins. Our results confirm that these new insulins allow the dose used to obtain diabetic control to be reduced and are advantageous in avoiding insulin allergy and lipoatrophy. Any long-term advantage in the reduced antigenicity to insulin and contaminating peptides remains to be established.

This work was supported by the British Diabetic Association.

\section{References}

1 Andreani, D, et al, Hormone and Metabolic Research, 1974, 6, 447.

2 Renold, A E, Winegrad, A I, and Martin, D B, Helvetica Chimica Acta, $1957,24,322$

${ }^{3}$ Watson, D, and Vines, R, Medical fournal of Australia, 1973, 1, 248.

${ }^{4}$ Asplin, C M, Hartog, M, and Goldie, D J, Diabetologia, 1978, 14, 99.

5 Deckert, T, Anderson, O O, and Poulsen, J E, Diabetologia, 1974, 10, 703

${ }^{6}$ Mustaffa, B E, Daggett, P R, and Nabarro, J D N, Diabetologia, 1977, 13, 311.

${ }^{7}$ Stowers, J M, and Logie, A W, British Medical fournal, 1976, 1, 879.

8 Tattersall, R, Prescribers' fournal, 1978, 18, 8 .

9 Teuscher, A, Diabetologia, 1974, 10, 211.

(Accepted 29 September 1978)

\section{What treatment is advised for diarrhoea caused by campylobacters?}

Campylobacters are responsible for an acute enteritis characterised by diarrhoea, in which the stool may be blood-stained, and abdominal pain that may be severe. The vast majority of these infections settle spontaneously behaving like salmonella enteritis, when specific antimicrobial treatment is not indicated but symptomatic treatment for relief of pain and abdominal discomfort is often required; in severe cases fluid and electrolyte replacement may be essential. In those patients with persistent diarrhoea who remain ill and feverish, it would be justified even in the absence of clinical trials to treat with a course of erythromycin stearate as recommended by Skirrow. ${ }^{1}$ These organisms are sensitive to several antibiotics including the aminoglycosides, and in the rare septicaemic case gentamicin would be a logical alternative to erythromycin.

${ }^{1}$ Skirrow, M B, British Medical fournal, 1977, 2, 9.

Is it still thought necessary to withhold breast milk for an hour or two before and after giving oral polio vaccine?

No restriction on breast-feeding in relation to oral poliovaccination is recommended in Britain. There has been speculation whether antibodies in colostrum or other inhibitors in breast milk might explain the lower "take" of the vaccine found in tropical countries, but recent investigations implicate an inhibitory substance in infants' saliva as the main factor. ${ }^{1}$ This problem in hot, developing countries may be countered by giving extra doses of oral vaccine or supplementary injections of inactivated vaccine. ${ }^{2}$ In Britain this problem is not real, and the extra ("boost") dose at school-entry is an additional safeguard.

1. Dömök, I, et al, Bulletin of the World Health Oranisation, 1970, 42, 405.
Melnick, J L, Bulletin of the World Health Organisation, 1978, 56, 21. 